\title{
From irradiance to output power fluctuations: the pv plant as a low pass filter
}

\author{
Javier Marcos ${ }^{1 *}$, Luis Marroyo ${ }^{1}$, Eduardo Lorenzo ${ }^{2}$, David Alvira ${ }^{3}$ and Eloisa Izco \\ 1 Dpto. Ingeniería Eléctrica y Electrónica, Universidad Pública de Navarra, Campus Arrosadia, Pamplona 31006 , Spain \\ 2 Instituto de Energía Solar, Grupo de Sistemas, ETSI Telecomunicación, Ciudad Universitaria, s/n, Madrid 28040, Spain \\ 3 Red Eléctrica de España, C/ Anabel Segura 11, Alcobendas 28108, Spain \\ 4 Acciona Solar, Avda. de la Ciudad de la Innovación, 3, 31621 Sarriguren, Navarra, Spain
}

\begin{abstract}
The power generated by large grid-connected photovoltaic (PV) plants depends greatly on the solar irradiance. This paper studies the effects of the solar irradiance variability analyzing experimental 1-s data collected throughout a year at six PV plants, totaling $18 \mathrm{MWp}$. Each PV plant was modeled as a first order filter function based on an analysis in the frequency domain of the irradiance data and the output power signals. An empiric expression which relates the filter parameters and the PV plant size has been proposed. This simple model has been successfully validated precisely determining the daily maximum output power fluctuation from incident irradiance measurements.
\end{abstract}

\section{KEYWORDS}

large PV plants; grid-connected; power fluctuations; spectral analysis; power simulation

\section{${ }^{*}$ Correspondence}

Javier Marcos, Edificio Los Pinos, Dpto. Ingeniería Eléctrica y Electrónica, Universidad Pública de Navarra, Campus Arrosadia, Pamplona 31006, Spain.

E-mail: javier.marcos@unavarra.es

\section{INTRODUCTION}

The power generated by photovoltaic (PV) plants has an intermittent character mainly due to the variability of cloudiness. As the penetration of PV energy in the utility grids increases, such intermittence might negatively affect the power quality and its reliability. Thus, the research interest in PV power fluctuations. Irradiance fluctuations have been analyzed in the frequency domain through wavelet transforms [1,2]. Other authors have analyzed power fluctuations in terms of power spectral density (PSD), i.e. frequency domain, using 2 months of 10 -s data and 2 years of 10 -min data from a single 4.6 MWp PV array and a $135-\mathrm{kWp}$ subarray within it. The main conclusion of these studies has been that the larger the PV plant, the bigger the attenuation of high frequencies [3].

Our work is based on a 1-year 1-s data of power output and in-plane irradiance from six PV plants located in Spain. The power of the plants ranges from 1 to $9.5 \mathrm{MWp}$, totaling $18 \mathrm{MWp}$ in 2009 . The plants under analysis are scattered over a $\sim 1000 \mathrm{~km}^{2}$ area in the south of Navarra (Spain). Distances between plants go from 6 to $60 \mathrm{~km}$. All the PV plants are equipped with vertical axis-trackers (azimuth) paralleling the sun east-west motion and each generator is tilted $45^{\circ}$ from the floor. The PV plants are connected to inject power to the $13.2 \mathrm{kV}$ grid. Power output $1 \mathrm{~s}$ data are obtained at the point of common coupling by means of a power meter (Allen-Bradley, Powermonitor), and are recorded by a PLC (Allen-Bradley, CompactLogix). Simultaneously, the short circuit current of a reference PV module situated around the middle of the PV plant provides a measurement of in-plane irradiance, which is also recorded. Additional details of the experimental set-up can be found in Reference [4].

In this paper, the PV plant power output is described as the signal output of a low pass filter where the input signal is the incident irradiance. The key point is that it is a first order filter and its pole value is a function of the PV plant area. This enables the simulation of the power fluctuations in any power network with any PV plant size, based solely on incident irradiance. 


\section{IRRADIANCE AND POWER SPECTRUM}

Figure 1 shows the irradiance, $G_{\mathrm{N}}$, and the output power, $P_{\mathrm{N}}$, recorded at the Milagro PV plant (9.5 MW generator peak power; 7.243 MW LV/MV transformer power, $P^{*}$ ), on 12 August, from 13:07 h to 13:20 h. Both signals have been previously normalized by $G^{*}=1000 \mathrm{~W} / \mathrm{m}^{2}$ and $P^{*}$, respectively. As expected, due to the big size of the PV plant in comparison with the discrete character of the irradiance sensor, the power curve is significantly smoother than the irradiance curve. Figure 2 shows, on a different time scale, the same signals, $G_{\mathrm{N}}$ and $P_{\mathrm{N}}$, along 14 days. The periodicity of the solar resource enables a Fourier analysis.

Figure 3 presents the Discrete Fourier Transform (DFT) of the irradiance signal, $G_{\mathrm{N}}$, recorded along a full year at the Milagro site, computed through a Fast Fourier Transform (FFT) algorithm. In general terms, for a time series of a measured variable, $x=x_{1} \ldots x_{N}$, the value at each point $x_{j}$ in the frequency domain, $X_{k}$, is obtained by Equation (1):

$$
X_{k}=\sum_{j=1}^{N} x_{j} \omega_{N}^{(j-1)(k-1)}
$$

where $N$ is the signal length and the $\omega_{N}$ is calculated according to Equation (2):

$$
\omega_{N}=e^{(-2 \pi i) / N}
$$

Following the suggestions made in Reference [4] and in order to reduce the variance in the coefficients $X_{k}$, the original signal is divided into several segments, 32 in our case. The coefficients, $X_{k}$, are calculated for each segment and then averaged at each frequency. Despite the fact that the Nyquist theorem states that DFT can be calculated up to a maximum frequency double the sample period, $0.5 \mathrm{~Hz}$ in our case, we restrict our analysis to $0.05 \mathrm{~Hz}$, which is large enough for our present objectives. The linear region of the

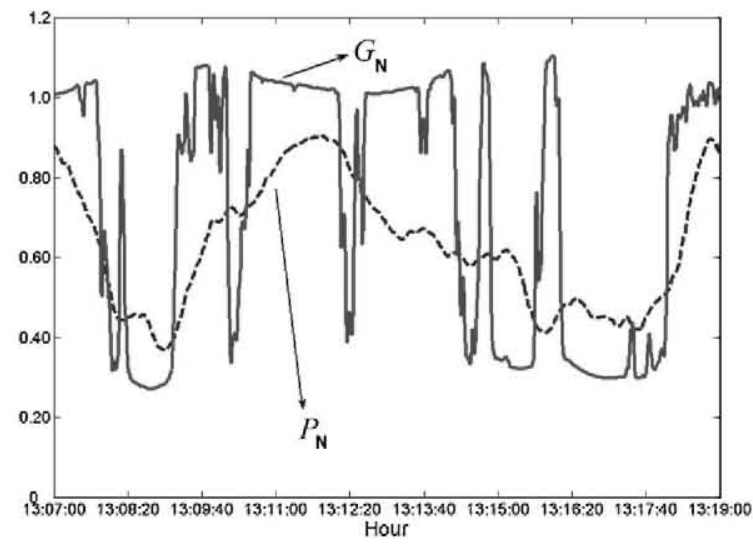

Figure 1. Irradiance, $G_{N}$, and output power, $P_{N}$, both normalized, recorded at Milagro site during a 15-min period on 12 August. (a)

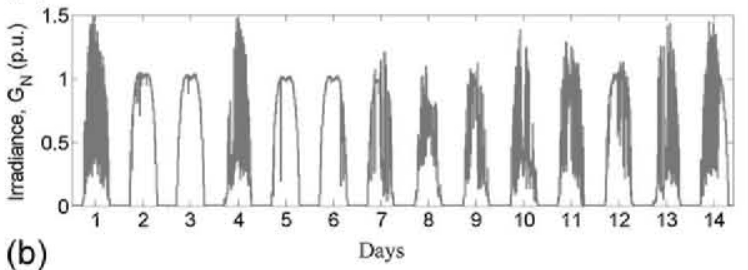

(b) Days

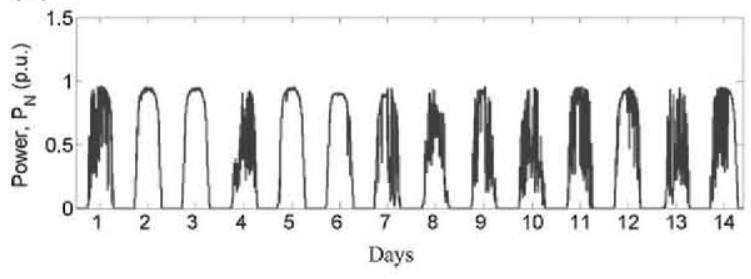

Figure 2. Irradiance $G_{N}$ (a) and output power $P_{N}$ (b) (both normalized) evolution during 14 days at Milagro.

spectrum fits a $f^{-0.7}$ function, which is in agreement with other author observations [3]. Cyclic daily availability of the solar resource is evidenced by a peak at $24 \mathrm{~h}$ $\left(1.15 \times 10^{-5} \mathrm{~Hz}\right)$.

The same frequency domain analysis is also applied to other previously normalized $\left(P_{\mathrm{N}}\right)$ PV plant power signals recorded during 2009. Figure 4 shows the power spectra calculated for the Milagro (9.5 MW; 7.243 MW) and the Sesma plants $(0.990 \mathrm{MW} ; 0.800 \mathrm{MW})$ as well as the irradiance spectrum previously showed in Figure 3. Now, some frequency intervals of the power spectra can be properly described as two linear regions well fitted by functions of the form $f^{-0.7}$ and $f^{-1.7}$, where the cross point defines the cut-off frequency, $f_{\mathrm{c}}$. In other words, regarding power fluctuations, the PV plant size can be interpreted as a first order low-pass filter for the irradiance signal. A similar

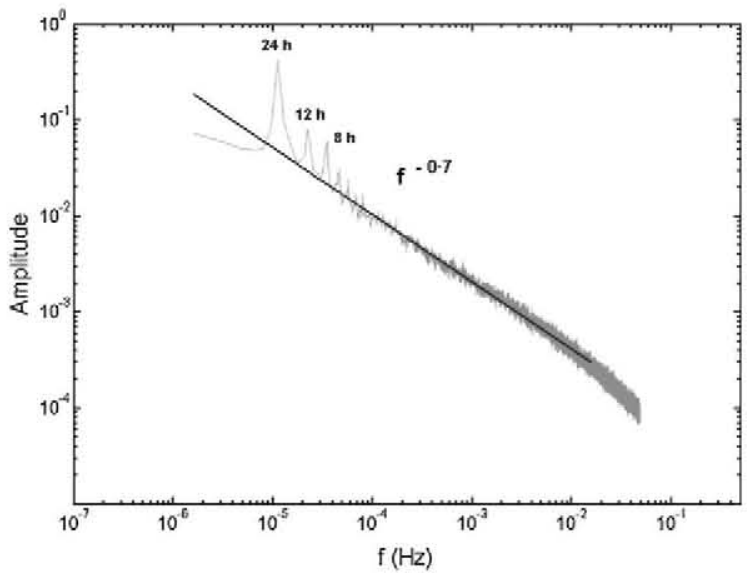

Figure 3. Spectra of the irradiance $G_{N}$ recorded at Milagro during 1 year. The linear region can be well fitted $\left(R^{2}=0.97\right)$ by a function of the form $f^{-0.7}$. 


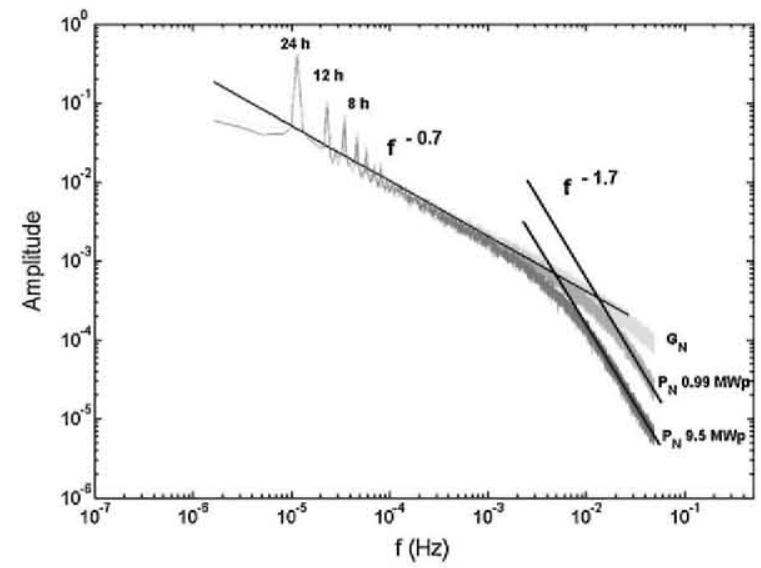

Figure 4. Spectrum of the irradiance $G_{N}$ recorded at Milagro, outpower $P_{\mathrm{N}}$ at Sesma $(0.99 \mathrm{MW} ; 0.8 \mathrm{MW})$ and Milagro (9.5 MW; $7.243 \mathrm{MW})$ during 1 year. The linear region for the larger frequencies of the power spectrums can be well fitted by a function of the form $f^{-1.7}$.

exercise is done for all the PV plants implicated, which have different areas and rated power sizes, $P^{*}$. Table I shows the values of the cut-off frequencies for each plant. As expected, the bigger the PV plant, the lower the cut-off frequency.

Note that the peak power and the area of the PV plant are closely related. In fact all the involved arrays are of the same type (one vertical axis tracking) and similar Ground Coverage Ratios (GCR), $\sim 0.18$. Figure 5 plots $f_{c}$, showed in Table I, versus the PV plant area, $S$. The curve at large frequencies is well fitted $\left(R^{2}=0.99\right)$ by a function of the form:

$$
f_{\mathrm{c}}=a \times S^{b}
$$



Figure 5. Cut-off frequency, $f_{c}$, as a function of the PV plant area, $S$. The tendency can be properly fitted $\left(R^{2}=0.99\right)$ by the function $f_{c}=a \cdot S^{b}$, where $a=0.020$ and $b=-0.499$.

where $a=0.0204$ and $b=-0.4997$, with $f_{\mathrm{c}}$ in Hertz and $S$ in hectares. In other words, the smoothing effect is practically given by a $1 / \sqrt{ } S$ law, which can be easily explained taking into consideration that shades typically move in one dimension while power is essentially related to surface or two dimensions.

The validity of Equation (3) is checked against a different PV plant located in another region: Socuellamos (Castilla La Mancha, $345 \mathrm{~km}$ distance from the nearest PV plant of the previous experiment), $2.6 \mathrm{MWp}$ (rated power of $1.975 \mathrm{MW}$ ) spread over $18 \mathrm{Ha}$. The cut-off frequency calculated by a Fourier analysis of a 1-s and 1-year data is $f_{\mathrm{c}}=0.0051 \mathrm{~Hz}$, which is in close agreement with $f_{\mathrm{c}}=0.0049 \mathrm{~Hz}$ given by Equation (3). It is worth noting that the Socuellamos PV plant GCR $=0.15$, is significantly lower than other plants. Considering the $f_{\mathrm{c}}$ values, it can be

Table I. Characteristics and cut-off frequency, $f_{\mathrm{c}}$ estimated for each PV plant.

\begin{tabular}{|c|c|c|c|c|c|}
\hline PV plants & Location (Lat; Lon) & $\begin{array}{c}\text { Peak power } \\
\quad(k W p)\end{array}$ & $\begin{array}{l}\text { Transformer power, } \\
\qquad P^{*}(\mathrm{~kW})\end{array}$ & $\begin{array}{l}\text { Area, } \\
S(\mathrm{Ha})\end{array}$ & $\begin{array}{c}\text { Cut-off frequency, } \\
f_{c}(\mathrm{~Hz})\end{array}$ \\
\hline Milagro Section 2 & $\begin{array}{l}42^{\circ} 15^{\prime} 28.24^{\prime \prime} \mathrm{N} \\
1^{\circ} 46^{\prime} 30^{\prime \prime} \mathrm{W}\end{array}$ & 143 & 100 & 0.63 & 0.026 \\
\hline Arguedas & $\begin{array}{l}42^{\circ} 10^{\prime} 32^{\prime \prime} \mathrm{N} \\
1^{\circ} 35^{\prime} 28^{\prime \prime} \mathrm{W}\end{array}$ & 958 & 775 & 4.1 & 0.0098 \\
\hline Sesma & $\begin{array}{l}42^{\circ} 27^{\prime} 43^{\prime \prime} \mathrm{N} \\
2^{\circ} 5^{\prime} 31^{\prime \prime} \mathrm{W}\end{array}$ & 990 & 800 & 4.2 & 0.0088 \\
\hline Cintruénigo & $\begin{array}{l}42^{\circ} 335^{\prime \prime} \mathrm{N} \\
1^{\circ} 47^{\prime} 50^{\prime \prime} \mathrm{W}\end{array}$ & 1438 & 1155 & 6.4 & 0.0081 \\
\hline Rada & $\begin{array}{l}42^{\circ} 19^{\prime} 3.25^{\prime \prime} \mathrm{N} \\
1^{\circ} 34^{\prime} 10^{\prime \prime} \mathrm{W}\end{array}$ & 1780 & 1400 & 8.7 & 0.0072 \\
\hline Castejón & $\begin{array}{l}42^{\circ} 9^{\prime} 7^{\prime \prime} \mathrm{N} \\
1^{\circ} 39^{\prime} 36^{\prime \prime} \mathrm{W}\end{array}$ & 2640 & 2000 & 11.8 & 0.0069 \\
\hline Milagro & $\begin{array}{l}42^{\circ} 15^{\prime} 28.24^{\prime \prime} \mathrm{N} \\
1^{\circ} 46^{\prime} 30^{\prime \prime} \mathrm{W}\end{array}$ & 9500 & 7243 & 52 & 0.0032 \\
\hline
\end{tabular}


Javier Marcos

Figure 6. Proposed transfer function for a PV plant with an area equal to $S$. The value of the pole $\tau$, has been replaced by the expresion $\tau=\left(2 \pi f_{c}\right)^{-1}$.



Figure 6. Proposed transfer function for a PV plant with an area equal to $S$. The value of the pole $\tau$, has been replaced by the expression $\tau=\left(2 \pi f_{c}\right)^{-1}$.

affirmed that the main power fluctuation smoothing factor is the plant area rather than its rated power.

\section{POWER FLUCTUATION SIMULATION}

For the measurements of a given irradiance time series, the power output could now be obtained via simulation, using the transfer function proposed for the PV plant under study (Figure 6). Note that the parameter $K$ corresponds to the relation $P^{*} / G^{*}\left[\mathrm{~m}^{2}\right]$ for the PV plant and the pole, $\tau$, has been replaced by the expression $\tau=\left(2 \pi f_{\mathrm{c}}\right)^{-1}$. As an example, Figure 7 shows the results from 12:30 to 15:00 on 25 October at the Milagro $(52 \mathrm{Ha})$ site. The upper plot shows the irradiance measured during that period. The lower plot compares the simulated and the real power data. The similitude is clearly observed. Such analysis has been extended to a full year data series. Figure 8 shows the DFT error. It can be observed that the error is below $2 \%$ for all the frequency range.

The validity of this simulation exercise is also checked in light of the maximum short-term (below $10 \mathrm{~min}$ ) daily power fluctuation, $\Delta P_{\Delta t \text { max }}$. Maximum power fluctuation along a day is of particular interest from the grid operator viewpoint [4]. The magnitude of a power fluctuation, $\Delta P_{\Delta t}$ $(t)$, at an instant $t$ for a given sampling period, $\Delta t$, is calculated as the difference between two power outputs normalized to the transformer power, $P^{*}$, of the plant under consideration, Equation (4). That is:

$$
\Delta P_{\Delta t}(t)=\frac{[P(t+\Delta t)-P(t)]}{P^{*}} \times 100
$$

We have defined the daily maximum power fluctuation error, $E_{\Delta t, d}$, as the difference between the real daily maximum power fluctuation $\Delta P_{\Delta t \text {,max, real }}$, and the simulated one, $\Delta P_{\Delta t, \text { max }, \text { sim }}$, Equation (5):

$$
E_{\Delta t, d}(\%)=\left[\Delta P_{\Delta t \max , \text { real }}-\Delta P_{\Delta t \max , \operatorname{sim}}\right]
$$

The annual evolution of $E_{\Delta t, d}$ is calculated; Table II shows the mean error and standard deviation for the 365 (a)

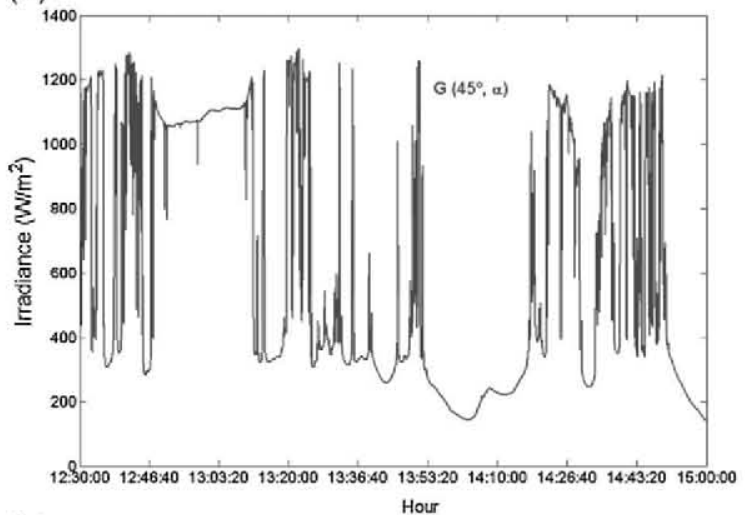

(b)

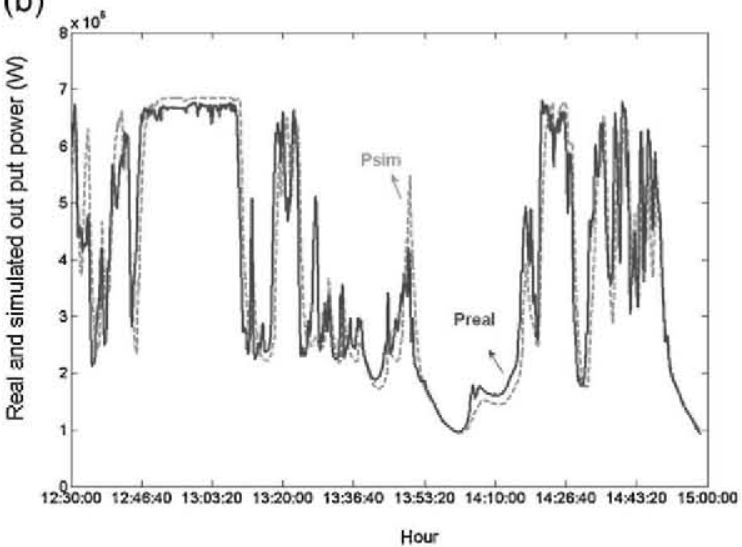

Figure 7. (a) Irradiance $G\left(45^{\circ}, \alpha\right)$ recorded from $12: 30 \mathrm{~h}$ to $15: 00 \mathrm{~h}$ on 25 October at Milagro $(52 \mathrm{Ha})$, (b) output real power, $P_{\text {real, }}$ (continue line) recorded during the same period at Milagro and output power simulated, $P_{\text {sim }}$ (dashed line) by the transfer function showed in Figure 6.

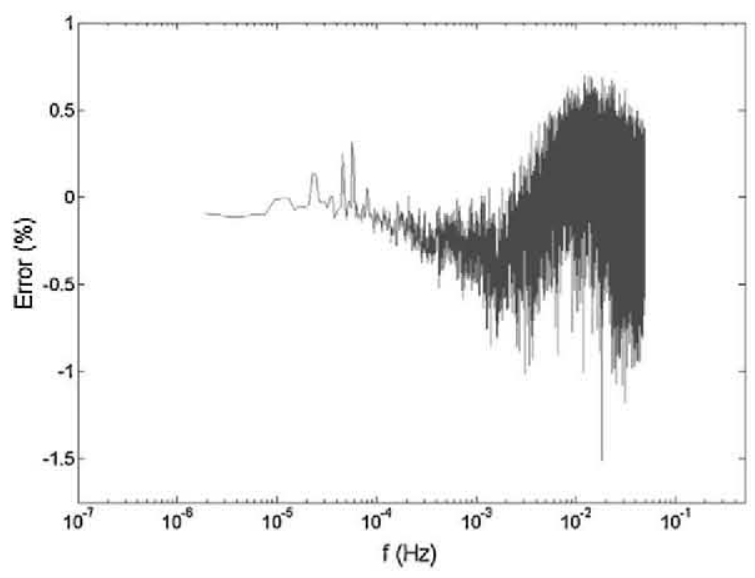

Figure 8. DFT error between real and simulated output power at Milagro for 1-year data. 
Table II. Mean error and standard deviation of the $365 E_{\Delta t r d}$ values obtained for different $\Delta t$.

\begin{tabular}{lcccrrrrrrr}
\hline$\Delta t(\mathrm{~s})$ & 1 & 2 & 5 & 10 & 20 & 40 & 60 & 120 & 300 & 600 \\
\hline Mean error (\%) & -0.54 & -0.6 & -0.8 & -1.2 & -1.7 & -2.2 & -2.1 & -0.8 & -0.09 & -0.07 \\
Standard deviation (\%) & 4.6 & 4.7 & 4.8 & 5.4 & 7.0 & 8.2 & 8.8 & 7.8 & 6.8 & 6.7 \\
\hline
\end{tabular}

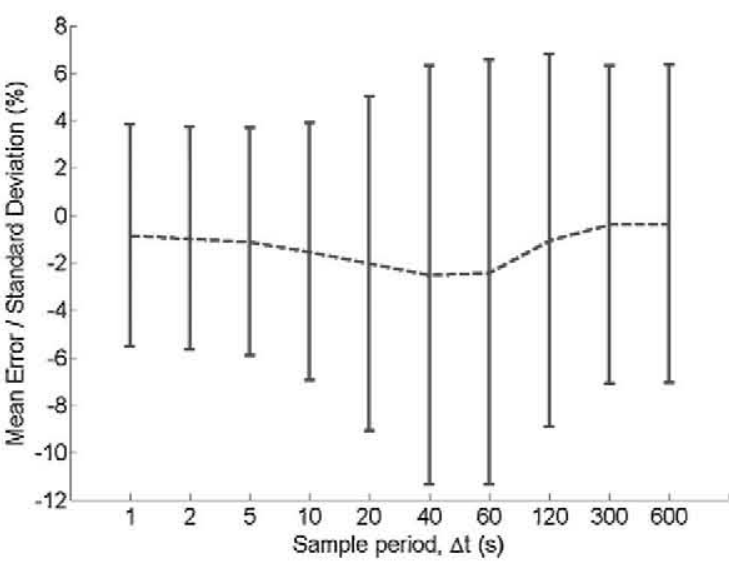

Figure 9. Mean error (dashed line) and standard deviation obtained for the annual evolution of the daily maximum power fluctuation error, $E_{\Delta t r d}$ ( 365 values in total for each $\left.\Delta t\right)$.

values of $E_{\Delta t, d}$ obtained for different $\Delta t$. Figure 9 compiles the corresponding values.

Finally, the histograms for the 365 daily maximum power fluctuations $\Delta \mathrm{P}_{\Delta t \text {,max,real }}$, and the simulated values, $\Delta \mathrm{P}_{\Delta t \text { max }, \text { sim }}$ are compared in Figure 10 , for $\Delta t=20$ and $600 \mathrm{~s}$. Since the frequency distributions are very similar, it can be concluded that the developed model is relatively precise, as well as simple.

\section{CONCLUSIONS AND OUTLOOK}

Power supply quality and network security could be seriously affected by power fluctuation of PV plants in a near future, due to the irradiance variability. The work of this paper is based on 1-year data with a 1-s resolution from six different PV plants (adding up to $18 \mathrm{MWp}$ installed). An analysis in the frequency domain of in-plane irradiance and output power has enabled the characterization of a PV plant as a first order filter. An empirical expression is proposed to calculate the value of the filter pole according to the PV plant extension. This simple model has been successfully used to determine the power output series of a PV plant of any size using only irradiance measurements. From the operator viewpoint, this can be a powerful tool to study the integration of PV plants in the power network, providing artificial power output series that can be used by the grid operator in his simulation programs. Maximum power fluctuation is the key to establish the maximum allowed PV penetration rate at a particular grid. In this paper, this parameter has been successful determined via simulation using solely incident irradiance measurements and the PV plant size.

In the same way, the model relates the output power and irradiance dynamics, as to be independent of the climatic region under consideration. In addition to this, the model has been validated for 1-year data, during which, any kind of irradiance profile has occurred and has been taken into account. Current research efforts deal with validating the model for other PV plant generator configurations. In particular, work is being done with 1 -s power output
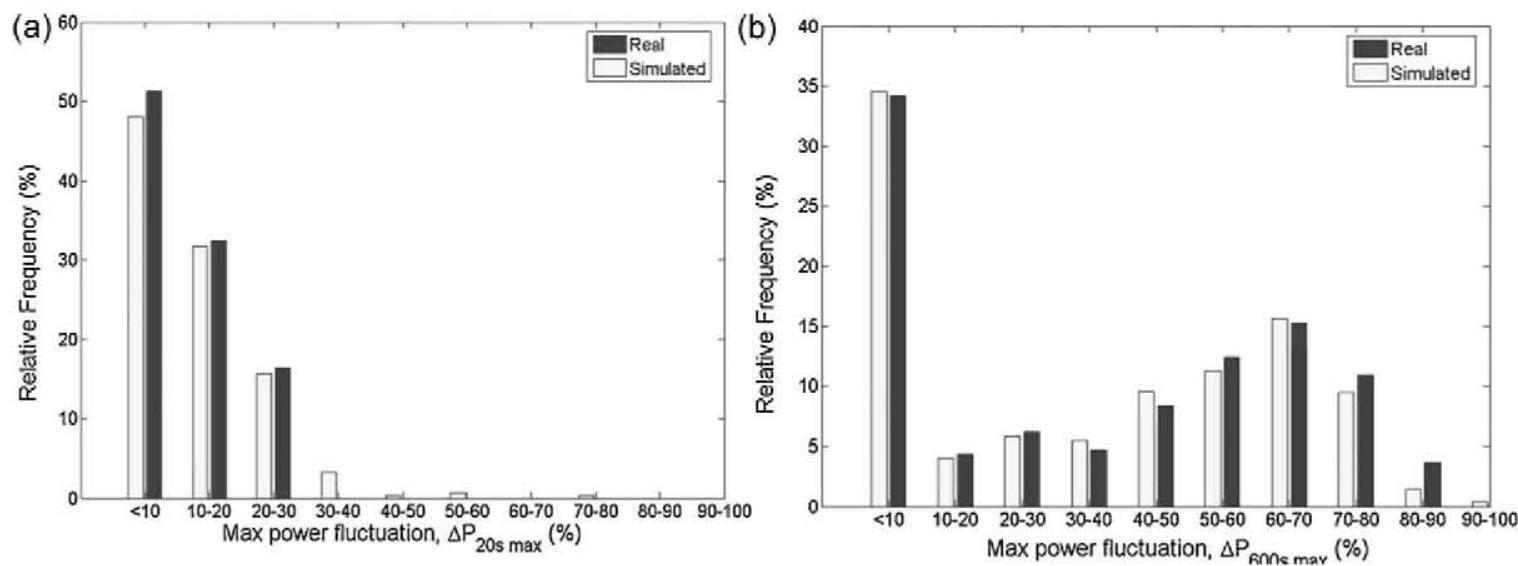

Figure 10. Histograms of the real maximum daily power fluctuation, $\Delta P_{M A X}$,REAL, observed during a year and the simulated, $\Delta P_{\text {MAX,Simulated }}$ for $\Delta t$ equal to $20 \mathrm{~s}$ (a) and $600 \mathrm{~s}$ (b). 
data from a non-tracked PV plant, Olmedilla $(60 \mathrm{MW})$. Initial findings confirm the validity of Ec. 3 for this configuration too and will be gathered in an up-coming publication.

\section{ACKNOWLEDGEMENTS}

The authors would like to thank Red Eléctrica de España (REE) for their financial support and ACCIONA for authorizing measurements at its PV plants and for their staff helpful collaboration. As well, Ramón García has provided precious theoretical support on the frequency domain analysis over the measured signals. Finally, it has to be mentioned that this work has also been supported by the Spanish Ministry of Education and Science (Grant number: DPI2009-14713-C03-01).

\section{REFERENCES}

1. Woyte A, Thong VV, Belmans R, Nijs J. Voltage fluctuations on distribution level introduced by photovoltaic systems. IEEE Transactions on Energy Conversion 2006; 21: 202-209.

2. Woyte A, Belmans R, Nijs J. Fluctuations in instantaneous clearness index: analysis and statistics. Solar Energy 2007; 81: 195-206.

3. Curtright E, Apt. J. The character of power output from utility-scale photovoltaic systems. Progress in Photovoltaics: Research and Applications 2008; 16: 241-247.

4. Marcos J, Marroyo L, Lorenzo E, Alvira D, Izco E. Power output fluctuations in large scale PV plants: one year observations with 1 second resolution and a derived analytic model. Progress in Photovoltaics. Accepted but not published. 